\title{
Pattern of Paediatric Dermatoses in a Tertiary Referral Centre, Nepal
}

\author{
Sharma R \\ Department of Dermatology, Civil Services Hospital, Kathmandu, Nepal
}

\begin{abstract}
Introduction: Dermatological problems constitute at least one third of all outpatient visits to a pediatrician and similar number of all visits to a dermatologist involve children.Children are often exposed to climatic and social conditions that make them more likely to develop skin infections and skin injuries.Little is known about the impact of pediatric skin disease on health care systems in developing countries like Nepal. So, data on this study can be useful in monitoring changes in disease trends in children and planning health care programs.

Objectives: To know the current status of disease trends and ethnic distribution of common dermatoses among children (hospital based) in this geographical locality.

Materials and Methods: All children, 14 years and below, attending the dermatology out-patient department with any dermatoses were enrolled in the study. The diagnosis was made by dermatologists based on detailed history and appropriate investigations. Patients were divided into four different age groups.

Results: A total of 424 children with skin related symptoms were enrolled in this study. The mean age of this population was 6.30 years and it ranged from 0.05 (19 days) to14 years. A total of 146 infective and 278 non-infective dermatoses were encountered as the primary diagnosis. Infections and infestations were the most common group of disorders (34.4\%, 146 cases), followed by dermatitis and eczemas (32.5\%, 138 cases). Fungal infections were the most common infective conditions $(11.6 \%, 49$ cases).

Conclusion: Infections and infestations were the most common etiologic group of disorders followed by dermatitis and eczemas. Fungal infections were the most common infective conditions followed by pyoderma.

Key words: Eczema; Ethnic Groups; Mycoses; Pyoderma; Nepal; Skin Diseases, Infectious
\end{abstract}

\section{Introduction}

A arge portion of our population constitute children that is vulnerable to a number of skin related problems. The pediatric population is quite sensitive and needs special care and focus. ${ }^{1}$ Skin problems in children can be acute or chronic and sometimes quite challenging for skin care professionals to manage. Morbidity and psychological problems are important issues in relation to chronic recalcitrant skin disorders that a treating dermatologist needs to consider. Skin health issues in children need special consideration compared to adult and elderly in terms of clinical presentation, treatment and prognosis. ${ }^{2}$

\footnotetext{
Address of Correspondence:

Dr. Rabindra Sharma

Registrar

Department of Dermatology

Civil Services Hospital, Kathmandu, Nepal

E-mail: sharmarabindra@rocketmail.com
}

Economy, climate, nutrition, environment and genetics are the key factors that greatly influence pattern as well as magnitude of skin related problems in predisposed children. ${ }^{3}$ Thus being aware of important differences that this particular age group demands in terms of skin health care compared to adults it becomes vital to estimate the burden and pattern of disease which

Submitted: $29^{\text {th }}$ September 2018

Accepted: $15^{\text {th }}$ January 2019

Published: $31^{\text {st }}$ March 2019

How to cite this article

Sharma R. Pattern of pediatric dermatoses in a tertiary referral centre, Nepal. Nepal Journal of Dermatology, Venereology and Leprology. 2019;17(1):39-41. doi: http://dx.doi.org/10.3126/ njdvl.v17i1.23249

\section{(c) (i)}

Licensed under CC BY 4.0 International License which permits use, distribution and reproduction in any medium, provided the original work is properly cited. 
affects not only the patient's life but also their families and society.

\section{Objectives}

This study was carried out to determine the pattern of common dermatoses in children who attended Dermatology clinic with skin related symptoms.

\section{Materials and Methods}

This was a hospital- based cross- sectional descriptive study carried out at out-patient department of the Department of Dermatology for a period of one year. A total of 424 patients with skin related symptoms presented to Dermatology OPD for check-up, and who fulfilled the set criteria were enrolled in this study. A questionnaire was prepared and details of the information were recorded according to the prepared proforma. The subjects or their guardian were interviewed and examined. The required investigations were performed as guided by the history and physical findings.

\section{Results}

A total number of 424 children with skin related symptoms were enrolled in this study. The mean age of this population was 6.30 years and it ranged from 0.05 (19 days) to 14 years. Male to female ratio was 1.14:1. Majority (52.9\%) of the study population were school children, $47.1 \%$ were pre-school children while $18.6 \%$ were infants. Age distribution is given in Table 2. A total of 146 infective and 278 non-infective dermatoses were encountered as the primary diagnosis. Infections and infestations were the most common group of disorders (34.4\%, 146 cases), followed by dermatitis and eczemas (32.5\%, 138 cases). Distribution of etiology of encountered dermatoses are given in Table 1. Various other dermatoses encountered were pigmentary disorders, insect bite reactions, disorders of hair and nails, miliaria, nutritional deficiency disorders, urticaria, genetic disorders, psoriasis, collagen vascular disease, hemangioma, drug eruption, pityriasis rosea and others. Fungal infections were the most common infective conditions (11.6\%, 49 cases). Among the various infections primary pyoderma involved $7.3 \%$ (31) cases and secondary pyoderma involved $4 \%$ (17) cases. Out of 33 cases $(7.8 \%)$ of viral infections common warts accounted for 3.3\% (14) cases, molluscum 2.4\%(10) cases, viral exanthem $1.2 \%$ (5) cases, herpes zoster $0.7 \%$ (3) cases and herpes simplex $0.2 \%$ (1) case. Dermatitis and eczema was the most common non-infective dermatoses. Among the
424 children most belonged to Brahmin ethnical class (32.8\%-139 cases). Chhetri, Giri and Thakuri comprised of $18.9 \%(80)$ cases. $11.3 \%$, (48) cases belonged to the Newar community. Other ethnic groups included Sherpa and Bhote 3.8\% (16) cases, Tamang 11.6\% (49) cases, Gurung 4.7\% (20) cases, Magar 6.4\% (27) cases, Rai and Subba 2.6\% (11) cases, B.K and Pariyar 3.8\% (16 ) cases, Tharu 0.7\% (3) cases, Muslim 0.7\% (3) cases and others.

Table 1: Distribution of Etiology of Various Dermatoses in Children

\begin{tabular}{|l|c|c|}
\hline Dermatoses & Frequency & Percent \\
\hline Infections and Infestations & 146 & 34.4 \\
\hline Dermatitis and Eczema & 138 & 32.5 \\
\hline Pigmentary disorders & 21 & 5.0 \\
\hline Insect bite reactions & 24 & 5.7 \\
\hline Disorders of hair and nails & 7 & 1.7 \\
\hline Miliaria & 13 & 3.1 \\
\hline Nutritional Deficiency & 1 & .2 \\
\hline Disorders & 8 & 1.9 \\
\hline Urticaria & 8 & 1.9 \\
\hline Genetic Disorders & 8 & 1.9 \\
\hline Psoriasis & 4 & .9 \\
\hline Collagen Vascular Disorders & 4 & .9 \\
\hline Hemangiomas & 1 & .2 \\
\hline Drug eruption & 1 & .2 \\
\hline Pityriasis Rosea & 40 & 9.4 \\
\hline Others & $\mathbf{4 2 4}$ & $\mathbf{1 0 0 . 0}$ \\
\hline Total & &
\end{tabular}

Table 2: Distribution of Dermatoses by age and sex.

\begin{tabular}{|l|c|c|c|c|}
\hline \multirow{2}{*}{ Diagnosis } & Age & \multicolumn{2}{|c|}{ sex } & \multirow{2}{*}{ Total } \\
\cline { 2 - 5 } & group & male & female & \\
\hline \multirow{4}{*}{ Infective } & $0-1$ & 11 & 4 & 15 \\
\cline { 2 - 5 } & $>1-5$ & 29 & 25 & 54 \\
\cline { 2 - 5 } & $>5-10$ & 24 & 25 & 49 \\
\cline { 2 - 5 } & $>10-14$ & 19 & 9 & 28 \\
\cline { 2 - 5 } Non- & Total & 83 & 63 & 146 \\
\hline \multirow{3}{*}{ infective age } & $0-1$ & 36 & 28 & 64 \\
\cline { 2 - 5 } & $>1-5$ & 35 & 32 & 67 \\
\cline { 2 - 5 } & $>5-10$ & 41 & 38 & 79 \\
\cline { 2 - 5 } & $>10-14$ & 31 & 37 & 68 \\
\hline & Total & $\mathbf{1 4 3}$ & $\mathbf{1 3 5}$ & $\mathbf{2 7 8}$ \\
\hline
\end{tabular}

\section{Discussion}

This study brings into focus the pattern of pediatric dermatoses encountered in a referral center in Nepal. The average age of this population was 6.30 and it ranged from 19 days-14 years. A total of 146 infective (34.43\%) and 278 non-infective cases (65.56\%) were encountered as the primary diagnosis. Negi et al in 
their study found that infections and infestations contributed to $50 \%$ of their cases. Various other authors have reported them occurring in the range of $35.6 \%$ to $85.2 \% .^{4}$ In all these studies, whether institution based or community based, the infections and infestations were the main group of dermatoses. The lower frequency of infections and infestations in our study could possibly be due to large urban population attending our hospital belonging to relatively higher socio-economic stratum. Incidence of eczemas and dermatitis was comparable with western studies where they ranged from $18 \%$ to $34 \% .{ }^{4}$ Atopic dermatitis accounted for $16.67 \%$ (23) cases of dermatitis and eczema which is $5.42 \%$ of the total children in this study. Studies from developed countries report incidence ranging from $3.1 \%$ to $28 \%$ thus the incidence of atopic dermatitis is similar to those of developed countries. ${ }^{5}$ This frequency of atopy may be related to the dietary habits and climate. Various similar studies done within Nepal do have similar results as our study. Neupane $S$ and colleague found infections followed by eczemas as the commonest pediatric dermatoses. ${ }^{6}$ Poudyal et al found fungal infections, eczema and acne as the three major pediatric dermatoses. ${ }^{7}$ Shresta $\mathrm{R}$ et al found eczema followed by urticaria, bacterial and viral infections as the commonest dermatoses among children. ${ }^{8}$ Genodermatoses were found to be higher than other similar studies. We encountered these dermatoses because our institute is a referral center. Moreover, the incidence of consanguineous marriage is high among certain ethnic population of our region. Lower frequency of urticaria may be due to differences in environmental exposure, dietary habits and climatic conditions. High frequency of papular urticarias was found because most of these children wear scanty clothing due to climatic conditions and thus being exposed to insect bites. ${ }^{4}$ Nutritional deficiency disorders accounted for $0.2 \%$ of patients which is not consistent with previous studies. The prevalence of nutritional disorders reflects our dietary habits. Acne prevalence is far too lower than that described in the literature may be due to lack of cosmetic concern. Prevalence of psoriasis, pigmentary disorders and miliaria were found to be similar to earlier studies. This study is simply a hospital based study in so it may not reflect the true disease prevalence in the community so further community based studies are recommended to know the true status of disease distribution pattern among age groups.

\section{Conclusion}

Infections and infestations were the most common etiologic group of disorders followed by dermatitis and eczemas. Fungal infections were the most common infective conditions followed by pyoderma. Among the fungal infections tinea capitis was the most prevalent condition. Primary pyoderma was more prevalent than secondary. Brahmins comprised the ethnic group with the highest prevalence of skin disorders.

Financial support: None.

Conflict of interest to disclosure: None declared.

\section{References}

1. Din T, Butt A, Bangash F, Abbas H. Burden of Skin Diseases at a Tertiary Care Hospital. Journal of Rawalpindi Medical College 2010;14(2):90-92.

2. Jain N, Khandpur S. Pediatric dermatoses in India. Indian J Dermatol Venereol Leprol 2010;76:4514. https://doi.org/10.4103/0378-6323.69034

3. Mohammed S, Elhassan M, Hussien K. The pattern of paediatric dermatoses among primary school children in Khartoum north, 2007. Sudanese journal of public health 2010;5:4.

4. Karthikeyan K, Thappa DM, B. Jeevankumar B. Pattern of Pediatric Dermatoses in a Referral Center in South India. Indian Pediatr. 2004; 41: 77-80.

5. Foley $P$, Zuo Y, Plunkett A, Marks R. The frequency of common dermatoses in preschool children

in Australia. Atopic dermatitis. Arch Dermatol. 2001; 137: 298- 300.

6. Neupane S Pandey P. Spectrum of dermatoses among paediatric patients in a teaching hospital of Western Nepal. Nepal Journal of Dermatology, Venereology \& Leprology. 2012; 10(1): 20-6. https://doi.org/10.3126/njdvl.v10i1.6419

7. Poudyal Y, Pathak S, Chaudhary N. Pattern of Pediatric Dermatoses in a Tertiary Care Hospital of Western Nepal. Dermatol Res Pract. 2016: 6306404. https://doi. org/10.1155/2016/6306404

8. Shrestha R, Shrestha D, Dhakal AK, Shakya, A, Shah SC, and Shakya H. Spectrum of pediatric dermatoses in tertiary care center in Nepal. Nepal Med Coll J. 2012; 14(2):146-8. 